\title{
Smart Classroom: Optimize and Innovative-Based on Compared with Traditional Classroom
}

\author{
Xin Wang, Mengyi Li, and Chuan Li
}

\begin{abstract}
With the development of China's reform and opening up for decades, China is gradually realizing informationization and scientificalization, and gradually popularizing these achievements to all aspects of society, such as intelligent transportation, intelligent communication and intelligent medical treatment. At the same time, with the rapid development of information technology, this achievement has also been widely used in the field of education and teaching. Smart classroom is the product of the deep combination of information technology and school education. This paper compares the smart classroom with the traditional classroom, and analyses the advantages of the smart classroom. The practical operation process of the smart classroom is embodied by the author's practical cases, so as to further highlight the advantages of the smart classroom.
\end{abstract}

Index Terms-Smart classroom, traditional classroom, technology.

\section{INTRODUCTION}

With the development of China's reform and opening up for decades, China is gradually realizing informationization and scientificalization, and gradually popularizing these achievements to all aspects of society, such as intelligent transportation, intelligent communication and intelligent medical treatment. At the same time, with the rapid development of information technology, this achievement has also been widely used in the field of education and teaching. Intelligent classroom is the product of the deep combination of information technology and school education.

In 2001, Max van Menan, a professor of education at the University of Albert, Canada, made education of wisdom a hot topic [1]. Since then, in 2008, IBM's A Smart Planets: the Next Leader Agenda (Palmisano 2008) [2] looked forward to the intelligent earth as the perception, Internet and intellectualization of everything on the earth. It also advocates five landmarks of wisdom education, namely learners' technology immersion; individualized and diversified learning paths; knowledge and skills of service-oriented economy; global integration of systems, culture and resources and important development in the $21 \mathrm{st}$

Manuscript received March 20, 2019; revised July 3, 2019.

Xin Wang is with the College of NBC Defense, No.1 Centre Street, Yangfang Town, Changping District, Beijing, China (e-mail: 3252415@qq.com).

Mengyi Li is with Central Conservatory Preparatory School, No.19 street Nanheyan, Dongcheng District, Beijing, China (corresponding author; e-mail: 06111my@163.com).

Chuan Li is with the Maternal and Child Health Hospital, No.19 Pingyuanli Community, Xicheng District, Beijing, China (e-mail: 40247988@qq.com). century [3], [4] (Rudd et al., 2009). In China, Qian Xuesen, a famous Chinese educator, began to advocate Dacheng wisdom as early as 1997 . It is to guide people to acquire wisdom and innovation ability as soon as possible. It emphasizes that wisdom consists of "quantity wisdom and quality wisdom", that is, the combination of logical thinking and image thinking [5]. As technology gradually moves towards intellectualization, ubiquitousness and perception, the large software products and hardware dealing with a wide spectrum of objects education have been developed, which is created on the requirement acquired by the teacher with regard to students needs [6], and quickly improves the intelligence of education and cultivate the ability of innovation [7].

Since the requirements and background of the information era, the so-called smart classroom refers to the mobile intelligent teaching mode that runs through pre-class, in-class and after-class under the support of the new generation of information technology, such as big data, cloud computing and internet, in order to cultivate students' independent learning, creative learning and personalized learning [8].

\section{Characteristics}

\section{A. Sharing of Quality Resources}

Electronic media can provide rich teaching resources, electronic courseware, micro-class, web page, pictures, etc. for the classroom. It can also use the current electronic communication application to share learning resources in time, and push relevant learning materials to students according to their different learning levels, so as to help improve learning efficiency, consolidate the knowledge learned, and promote the absorption of knowledge.

\section{B. Timely Teacher-Student Interaction [9], [10]}

At present, there are diversified communication tools, which can be used in smart classes to set up student discussion groups. After class, students can communicate with teachers through electronic devices to answer questions in time, so as to ensure that questions are not left behind, accelerate learning efficiency and improve learning ability.

\section{Feedback and Analysis of Big Data}

Smart classroom can use big data to analyze students' learning situation, and get data analysis, so as to have a clear understanding of students' learning situation from all angles. And according to the results of the analysis and different levels to provide students with personalized learning programs and materials, it will help to achieve the stratified teaching and personalized learning. 


\section{AdVAnTAges of SMART ClassRoOM: COMPARISON WITH TRADITIONAL CLASSROOM}

Smart classroom has its own advantages, especially when compared with traditional classroom. Traditional classes are mainly divided into preparing lessons, lecturing, assigning homework, correcting homework, and after-school counseling. However, the smart class is more inclined to complete teaching before, during and after class. Combining the different characteristics of the two classes, I want to compare them in the following aspects:

\section{A. Teaching Ideas}

The concept of traditional classroom mainly depends on teachers, textbooks and classroom. Teachers prepare lessons, design teaching process and prepare teaching materials before class. Classroom activities are organized according to instructional design to help students learn new knowledge and review old knowledge. Among them, the classroom is the main part in the whole teaching process and the teaching knowledge through the teacher's instillation. But the smart classroom is mainly centered on students, practice and creation. Through the use of network multimedia, students are regarded as the center of teaching, students' habit of self-study is cultivated, and the cultivation of practical ability and innovative ability is emphasized.

\section{B. Teaching Methods}

Traditional classroom teaching method is still based on traditional inculcation. Teachers and classrooms are the leading ways to teach mechanically knowledge to students, and then consolidate it through repeated classroom and after-class exercises. Although with the renewal of teaching ideas, traditional classroom teaching methods also gradually pay attention to the guidance of knowledge learning, but it is still difficult to escape the indoctrination of teaching methods. Smart classroom, the initiative of learning is exchanged to students, students become the center of knowledge learning, and the classroom as a place to test the effect of knowledge learning and practice, only play a supporting role. Teachers externalize and share individual precipitated knowledge to students through Internet multimedia, and students learn and discuss it independently. In this process, teachers change from the master of teaching to the organizer, instructor and helper of teaching, and give the initiative of learning to students.

\section{Studying Methods}

Similarly, in the traditional classroom, students are passive receivers of knowledge, often through the links arranged by teachers through repeated exercises to obtain knowledge. The whole process is relatively passive and lacks the sense of independence. Moreover, because of the passive learning method, students' practical ability is limited. In the smart classroom, students become active constructors. With the student-centered teaching method and the experiential learning of cultivating students' core literacy, students become more active in the process of learning, combining their learning habits and learning abilities, and actively explore knowledge in a group or individual way. The whole learning process is more social, interesting, competitive, research and collaborative.

\section{Learning Resources}

In the traditional classroom, learning resources are often limited to textbooks, relevant exercise books, teaching PPT, various test papers, etc. The vast majority of learning resources come from the relevant information offline. Relatively speaking, it is not flexible enough and resources are not abundant enough. Smart classroom however have realized the interconnection and interoperability with high-quality educational resources on the Internet. Video materials, micro-classes, web pages, audio and electronic courseware are all resources involved and utilized in smart classes. Various forms, for students, learning can also increase their interest and motivation. Learning resources have become more open and diverse.

\section{E. Learning Evaluation}

The traditional classroom learning evaluation is relatively single. The most common way is the form of examination, which summarizes the students' learning situation roughly and guides the teaching. In addition, classroom tests are often used, such as oral answers and written answers. Although the testing methods are constantly improving and different evaluation methods are added, it is often difficult to achieve a fine and effective evaluation of students' level in the end. On the contrary, the smart classroom mainly controls the students' learning situation through three stages. In the three stages of pre-class, in-class and after-class, through the analysis of wrong questions and class interaction, the use of intelligent learning system for data diagnosis can clearly reflect students' weaknesses, learning fluctuations, and bad learning habits. Make the evaluation of students more accurate [11], and then teachers give more scientific data feedback.

The summary of the comparison between the traditional classroom and smart classroom is showed in Fig. 1.

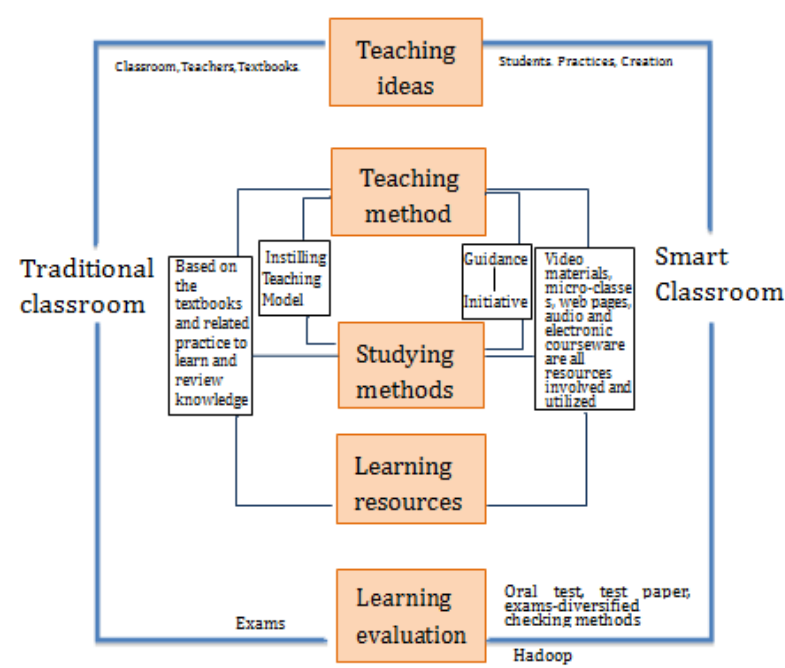

Fig. 1. Comparison between the traditional classroom and the smart classroom.

\section{PRACTICE}

In a comprehensive English teaching classroom, the author takes media censorship as the theme, aiming to guide students to learn the essentials of blog writing, and to 
cultivate students 'oral and critical thinking.

\section{A. Before Class Time}

In order to understand the students' understanding of the media censorship system before class, teachers use the Youxuepai app of the smart classroom of teachers version to make the relevant vocabulary of media censorship into test questions and share them to the students, so that the students could take independent tests, and then collect the test results of the students to analyze the students' vocabulary level and grade the students' vocabulary level. Then, in the software, students are offered to the relevant articles on the website called Newsela, and the vocabulary level of the articles will adjust according to different Lexile level of the students, which includes words' level of max, 1040L, 980L, 840L, and 590L. In the class being taught, students' English are in the fundamental level, so teachers choose 590L. And then students are asked to write a microblog on media censorship after reading and discuss the topic. The Fig. 2 shows the different words with different Lexile level between 590L and 1040L.

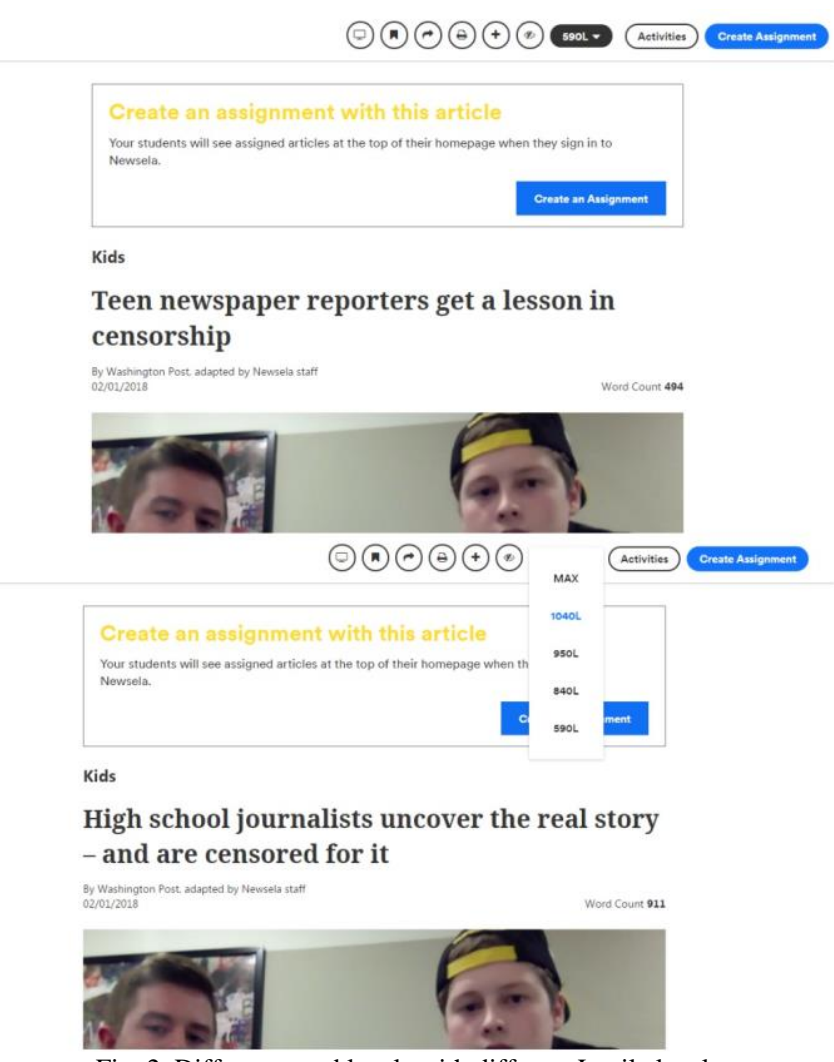

Fig. 2. Different word levels with different Lexile levels.

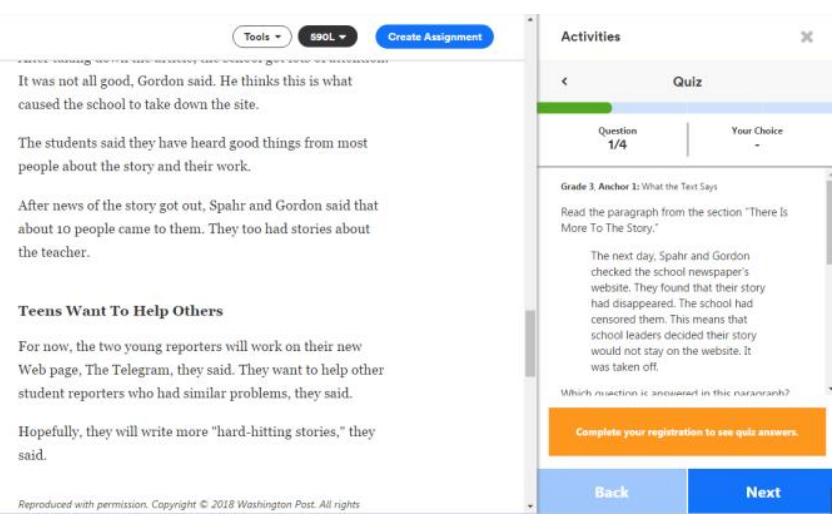

Fig. 3. Reading questions shown on the right side.
After reading the article by students themselves, several reading questions are given to check if they understand the passage well shown in Fig. 3. And according to the data about the result of 4 questions, teachers can know whether students understand the passage by themselves and which part is the most difficulty for them. In the Fig. 4, it shows that almost $85 \%$ can answer three out of four questions correctly and $70 \%$ studnets can understand the meaning of related words given at the beginning in Youxuepai app, which means students can write a microblog about media censorship based on what they read in this passage.

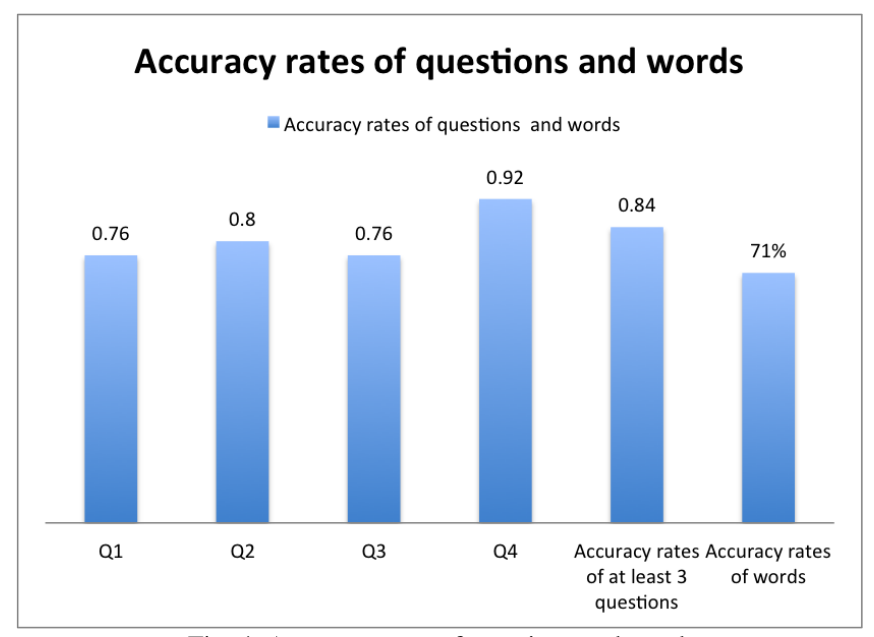

Fig. 4. Accuracy rates of questions and word.

\section{B. During the Class Time}

During the class time, the teacher will grade and analyze the articles written by the students who have been checked, and summarize the answers to the questions in the writing format. Then teachers divide the students into groups and give them a discussion according to the content of their articles. During the class time, teachers encourage different opinions and select group leaders to ensure that every member has the opportunity to speak.

Then, members of the group exchange views. Finally, the group members put their ideas on the student-side app, and the teacher checked them and gave them a group evaluation.

Finally, each student exchanges blog articles with each other, and comments on the blog of the students as comments, and as homework.

\section{After the Class Time}

After class, the teacher summarizes the relevant vocabulary in the classroom and examines the students, and shares the relevant new reading questions of media censorship to the students for testing, and then input data analysis.

After a class, the students have a clear understanding of the blog and the way they express their opinions. In Fig. 5, the comparison of accuracy of the questions and words between the result before reading and the result after reading is shown to see how much students can improve after the class. And teachers give students an extended reading material related as the homework and collect the result as well. The specific results are in Fig. 6 as follow:

As the reading results shown in the figures, it indicates that after the class with the help of smart equipment, three 
consequences can be seen. First, students have a better understanding about the passage in the website according to the increase accuracy rate of questions and words. After the class, students can catch the meaning of related words more effectively, and figure out the gist and details of the reading passage more efficiently and accurately. Second, because students should summarize their own ideas as a form of a microblog and also after discussing with classmate during the class, and they have to write the comments to others blog, this is a way to show their extra ideas about the topic of media censorship. This can cultivate a sense of critic thinking for students and also improve their writing skill. Third, the speaking skill can also be improved in logical and rigorous way by the discussion in the class, which helps students to learn to show their own idea fluently.

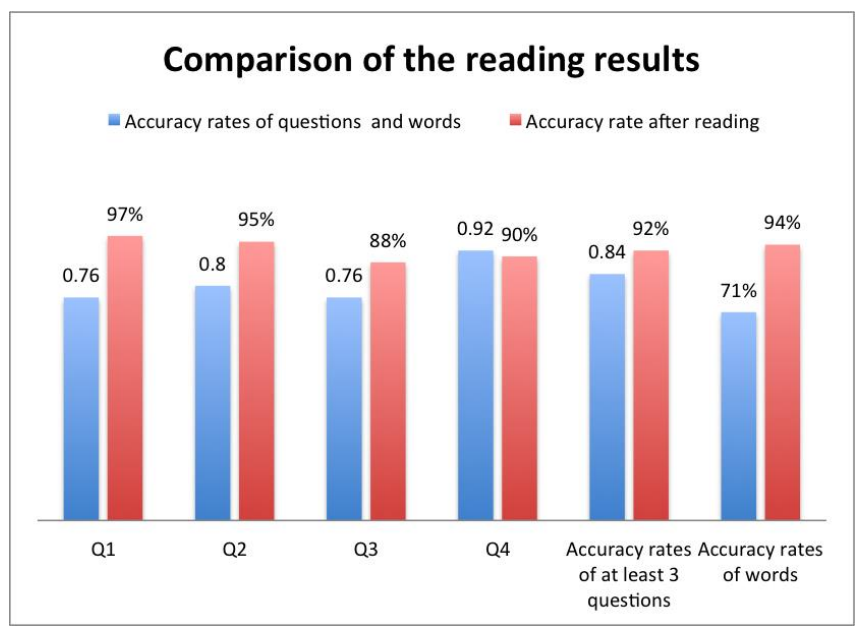

Fig. 5. Comparison of the reading results.

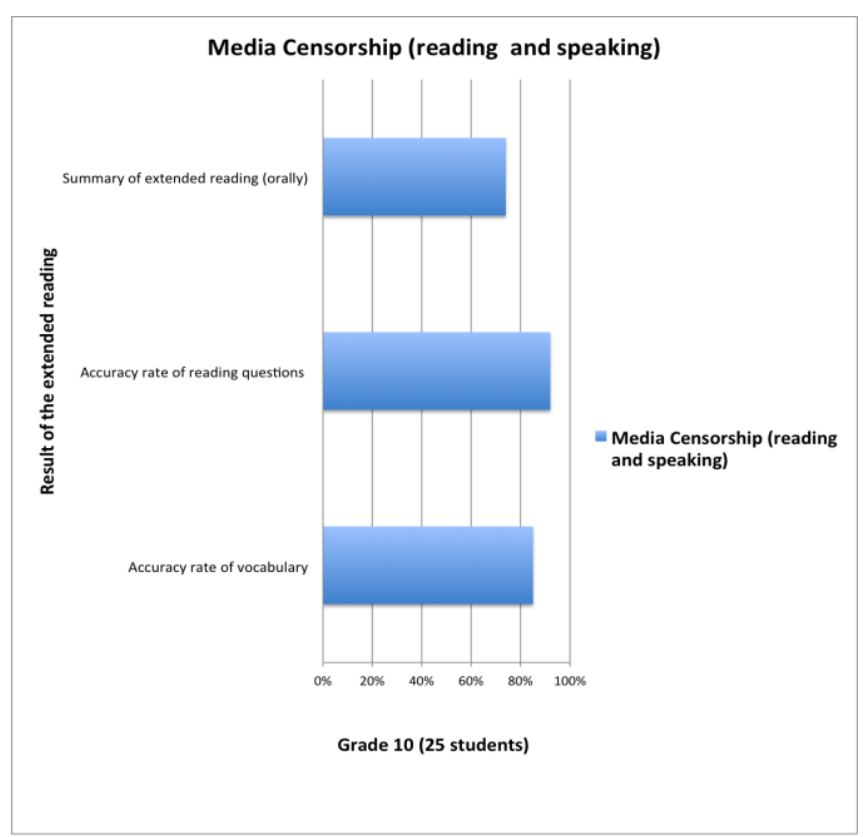

Fig 6. Result of the Extended reading.

\section{CONCLUSION}

Based on the practical case study below, the result of the teaching is quite good and effective about the vocabulary memory, reading comprehension and critical thinking training in the English teaching of smart classroom. Students can better integrate vocabulary into the use of real language and have a stronger memory through repeated exercises and contextual memory. In terms of reading, pre-class preparation, in-class analysis and explanation, and after-class evaluation help students to understand the article more independently, which help them learn well from the beginning of the overall grasp of the main idea to the details taught in the class, as well as the understanding of the core of the article, which makes a comprehensive understanding of the article [12]. In addition, the skills of English listening, speaking, reading and writing can also be cultivated through the integration of writing or oral practice. In critical thinking, in the process of understanding the core of the article, group discussion and sharing of media resources can guide students to think dialectically from different perspectives and let them to brainstorm, digging deeply into cultural content, and then gradually cultivate critical thinking. This way can be used to the teaching of various disciplines.

With the rapid development of smart classroom, there are new requirements for all aspects of education. In the implementation of smart classroom, we should pay attention to the need for supporting related hardware. The arrangement of classroom, the requirement of electronic version [13], the requirement of network and the matching of students' electronic equipments are all needed in the intelligent classroom [14], [15]. In addition, how to adapt to the requirements of smart classroom has also put forward corresponding requirements for teachers. Teachers should know how to improve their new scientific and technological level, how to optimize their teaching level, and how to interact with students in a benign way will be a new topic through smart equipment.

Based on the observation of the current social development, the development of intelligent classroom has become an inevitable trend, which will also lead the innovation of the educational era.

\section{CONFLICT OF INTEREST}

The authors declare no conflict of interest.

\section{AUTHOR CONTRIBUTIONS}

Xin Wang chose the theme and conducted the research; Mengyi Li collected the materials and wrote the paper; Chuan $\mathrm{Li}$ analyzed the data; all authors had approved the final version.

\section{REFERENCES}

[1] M. Menan, Teaching Wisdom-the Implication of Educational Wisdom, Compared with Beijing: Educational Science Press, 2001, pp. 196-198.

[2] G. Q. Deng, "Personalized learning of students in "wisdom classroom"," Information Technology, December 2013.

[3] Z. T. Zhu, "Wisdom classroom new development: from flipping classroom to wisdom classroom and wisdom learning space," Open Education Research, vol. 22, no 1, February 2016.

[4] M. King et al. (2009). Education for a Smart Planet: The Future of Learning. [Online]. Available: http://www.red-books.ibm.com/redpapers/pdfs/redp4564.pdf

[5] X. M. Qian, "Qian Xuesen's exploration of "Dacheng Wisdom" Commemoration of Qian Xuesen's centenary birthday," Scientific Research, vol. 31, no. 6, November 2011.

[6] E. Milko, "Multimedia application effective support of education," presented at 9th International Scientific Conference on Distance Learning in Applied Informatics, 2012. 
[7] B. He, "Intelligent learning: connotation, evolution and trend Learner's perspective," Electrified Education, no. 11, pp. 24-33, November 2013

[8] J. Liu, "Wisdom classroom: the new direction of school classroom development in the era of "Internet +"," Audio-Visual Education in China, no. 366, July 2017.

[9] T. Chen, "Design and application of intelligent classroom teaching mode under the background of Internet + education," Jiangsu Normal University, May 2017.

[10] C. Y. Zhong, "Design and application of intelligence-based classroom teaching model - Taking English listening and speaking as an example," Guanghua University, June 2018.

[11] W. Xie, Y. Shi, G. Xu, and D. Xie, "Smart classroom - An intelligent environment for tele-education," in Proc. the Second IEEE Pacific Rim Conference on Multimedia Bejing, pp. 662-668, 2001.

[12] M. Luo, "A survey on the current situation of teacher-student interaction in junior high school English classes under the model of intelligent classroom - Taking a school in Hanzhong as an example," Shanghai University of Technology, June 2018.

[13] D. Marilla et al., The Importance of Physical Space in Creating Supportive Learning Environments, San Francisco: Jossey-Bass, 2002.

[14] J. Aguilar, P. Valdiviezo, J. Cordero, and M. Sanchez, "Conceptual design of a smart classroom based on multiagent systems," Int'l Conf. Artificial Intelligence, p. 471

[15] M. Sánchez and J. Aguilar, "AmICL — Middleware reflexivo para ambientes inteligentes de aprendizaje en la nube," Mérida, Venezuela, June 2014

Copyright $(92019$ by the authors. This is an open access article distributed under the Creative Commons Attribution License which permits unrestricted use, distribution, and reproduction in any medium, provided the original work is properly cited (CC BY 4.0).

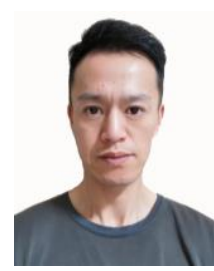

Xin Wang was born on March 24, 1981 in Shaoyang, Hunan province. He got the master degree of NBC defense in Fanghua college in Beijing. $\mathrm{He}$ is an associate professor at the College of the NBC Defense.

Prof. Wang has published a lot of papers in several academic researches and written several books in his researching field. He has participated in major national scientific research missions on many occasions. He has won two second-class prizes for scientific and technological progress, seven third-class prizes and one third-class prize for teaching achievements.

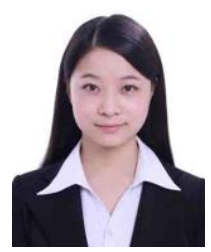

Mengyi Li was born on April 28, 1989 in Changsha, Hunan province. She got the master degree of diplomacy in Beijing Foreign Studies University in 2015.

She is an English teacher at the Central Conservatory Preparatory School. She has been a teacher for 4 years after she graduated from the universities, and is interested in education and teaching.

Ms. Li got two certificates of Integrating Critical Thinking into the Exploration of Culture in an EFL Setting and Teaching Grammar Communicatively from the American English e-Teacher Program.

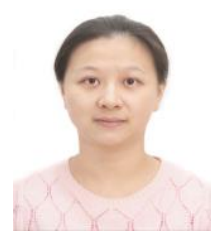

Chuan Li was born on November 15, 1984 in Changsha, Hunan province. She got the bachelor degree of clinical medicine in Zunyi Medicine University in Zhuhai, Guangdong province.

She is an attending doctor at the Maternal and Child Health Hospital. She has been a doctor of children for more than 10 years, and is professional in the field of children's physiological and psychological health.

She got the first place in Beijing Children and Women Medicine Competition with two times. 